\title{
Recovery on a Drug Discrimination Learning Task After Brain Transplants: Preliminary Findings
}

\author{
M. López Cabrera, D.N. Velázquez Martínez, O. Zamora, G. Cornejo, \\ A. Segoviano, F. Ostrosky and I. Madrazo \\ Depto. Psicofisiolog 1́, Facultad de Psicolog 1a; Depto. Farmacolog fa, Facultad de Medicina, Universidad \\ Nacional Autónoma de Mexico y Centro Medico Siglo XXI, Mexico.
}

Brain grafts may improve functional recovery after brain damage. The recovery has been evaluated by morphological and behavioral observations, but such evaluations of recovery have some problems since the demonstration of cellular growth in the graft is different from cellular functionality. For example, the graft may facilitate behavioral expression of related brain areas.

The drug discrimination learning paradigm may be a useful technique to evaluate functional recovery because, in order to perceive and discriminate the drug conditions, the following are required: a) specific pharmacological mechanisms (membrane receptors) at the cellular level; b) specific brain areas on which the receptors, brain pathways and physiological mechanisms are located for the organization of the response, and c) specific behavioral responses which may provide an index of the functionality of receptors as well as of brain areas.

Subjects were male Wistar rats with a body weight of $350-400 \mathrm{~g}$. The animals had free access to food but were deprived of water during 22 $\mathrm{h} /$ day. Water was provided in a $30 \mathrm{~min}$ session five days a week and $1.5 \mathrm{~h}$ of free access. The rats were trained on two operant conditioning chambers, each equipped with two levers on a MULT FR10-FR10 to discriminate between scopolamine $(1.8 \mathrm{mg} / \mathrm{kg}$ s.c. $20 \mathrm{~min}$ before session) and vehicle (saline) on randomly alternated days. Injection volumes were 1.0 $\mathrm{ml} / \mathrm{kg}$. Drug condition was the discriminative stimulus for correct lever selection and training was extended until no more than 2 incorrect lever presses were emitted before the first reinforcer $(0.3 \mathrm{ml})$ of the session. After training rats were lesioned bilaterally in the hippocampus (AP -2.3 Bregma, L 0.9, V -4.3 Surface, /1/). One month after lesion, the drug discrimination was reevaluated under the saline and scopolamine conditions. The subjects received a 17-day fetal homologous transplant in the same site as the lesion. Fourteen days after transplantation, rats were deprived of water for evaluation on the drug discrimination task (under the same conditions as training).

Experimental events (reinforcer, light) were controlled with computer equipment. Responses and time of occurrence were registered for each lever. A drug discrimination index (DDI) was calculated (saline lever presses/drug + saline lever presses) before the first reinforcer of each session.

After approximately 40 sessions on each drug condition, rats learned to discriminate drug conditions. Response rate and time to first reinforcer were about the same on saline and scopolamine days, showing that the drug did not interfere with performance or motivational variables. On the last five days of training the DDI (of five rats which completed all the experimental series) was 0.994 on saline and 0.006 on scopolamine days. Response rate and time to first reinforcer were about the same on saline and scopolamine days showing that the drug did not interfere with performance or motivational variables. After lesion, the rats responded randomly to the levers; the DDI was 0.370 for saline and 0.485 for scopolamine sessions, whereas the time to the first reinforcer increased and the response rate decreased. The DDI tended to return to pre-lesion values after brain transplants $(0.860$ for saline and 0.164 for scopolamine) whereas impairment persisted 
since no changes were observed for rate or time to first reinforcer. Results yielded significant differences on the DDI after two-way ANOVA (drug condition vs lesion-transplant) at $\mathrm{p}<0.01$; Duncan tests revealed significant differences between the lesion and training for the DDI on both saline and drug conditions. In the saline condition, the DDI after the transplant differed from lesion but not for the training condition, whereas in the drug condition the DDI differed from lesion but was still different from training condition.

In conclusion, the lesion to the hippocampus did interfere with the drug discrimination task. After fetal homologous transplants the DDIs were similar to the training conditions; however, although the rats did respond correctly, there was a reduction in the response rate. The drug discrimination paradigm may be a useful model to evaluate recovery after brain grafts and may serve to distinguish between motor or motivational factors and cognitive factors.

\section{ACKNOWLEDGEMENTS}

This work was supported by a grant from PADEP / DGAPA - UNAM and CONACYT 0772-H0109.

\section{REFERENCE}

1. Paxinos G, Watson $C$. The rat brain in stereotaxic coordinates, 2nd ed.. New York: Academic Press, 1986. 

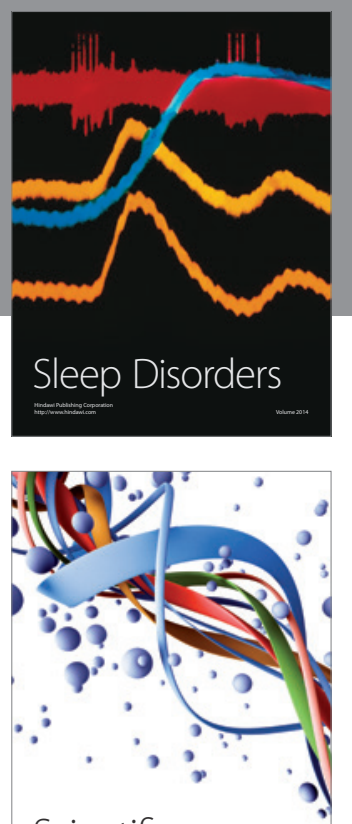

Scientifica
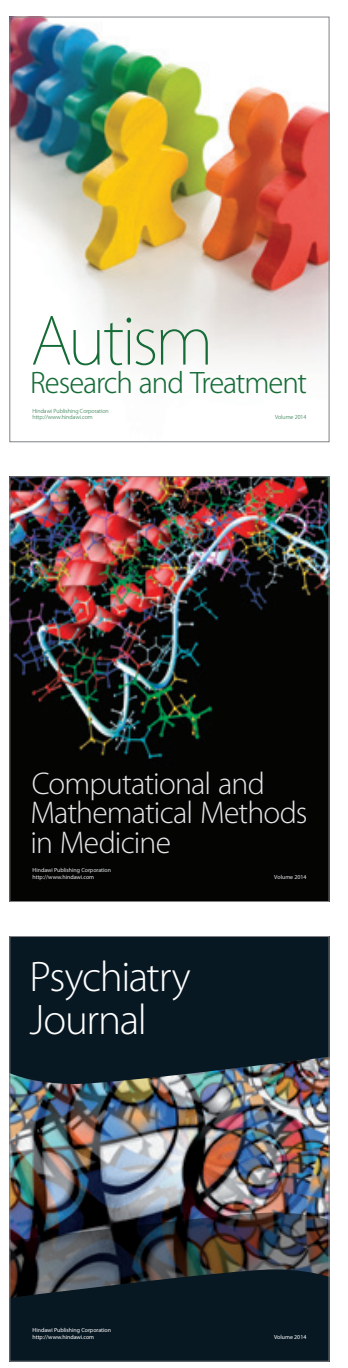
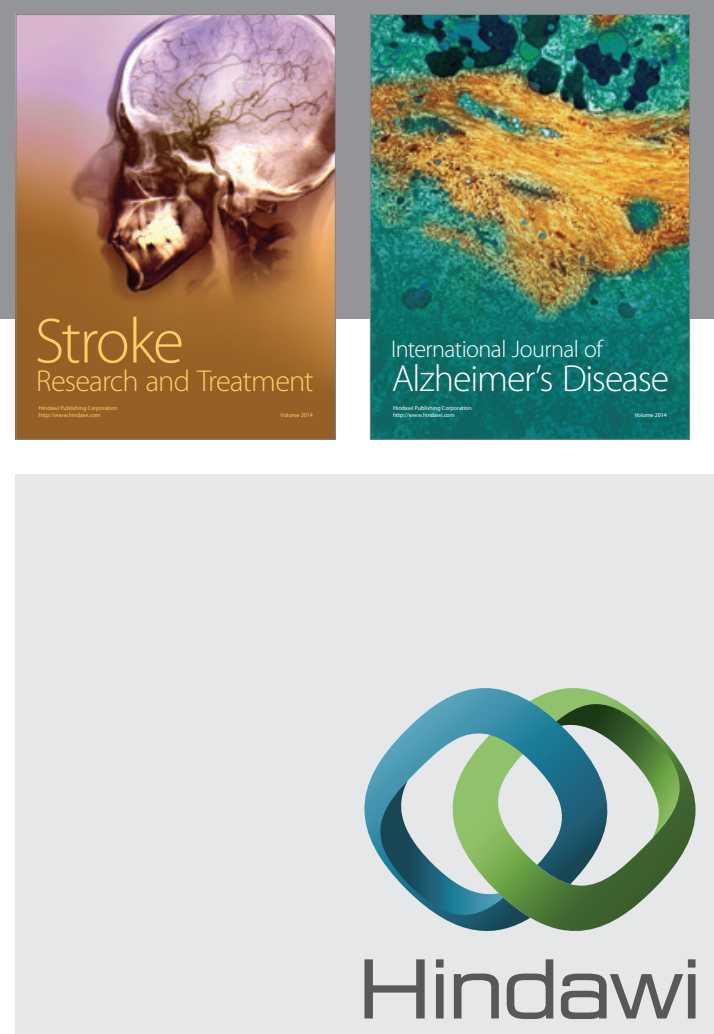

Submit your manuscripts at

http://www.hindawi.com
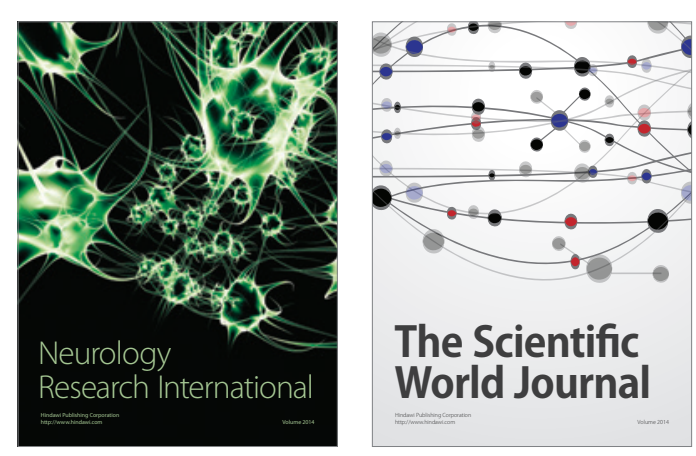

The Scientific World Journal

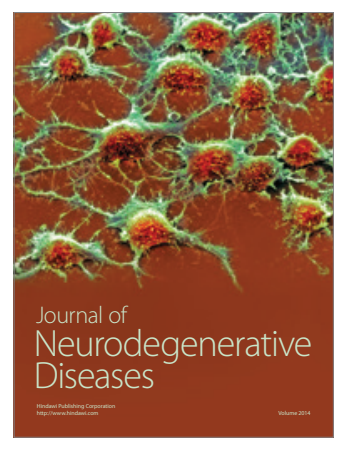

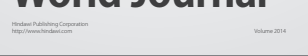

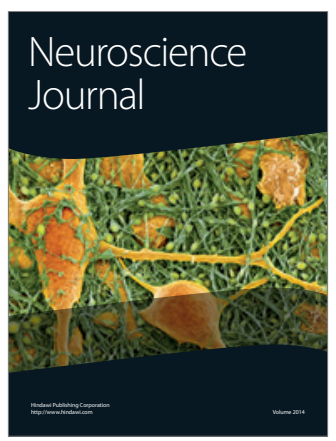

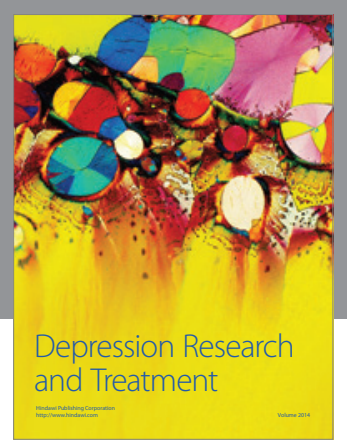
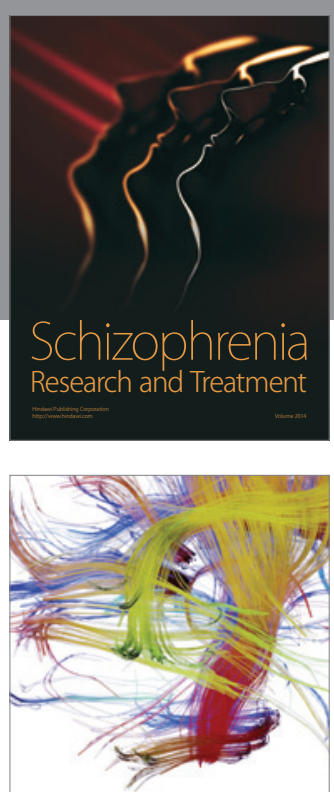

Brain Science

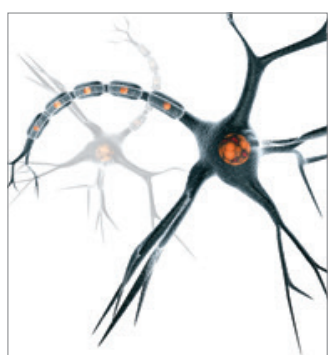

Neural Plasticity
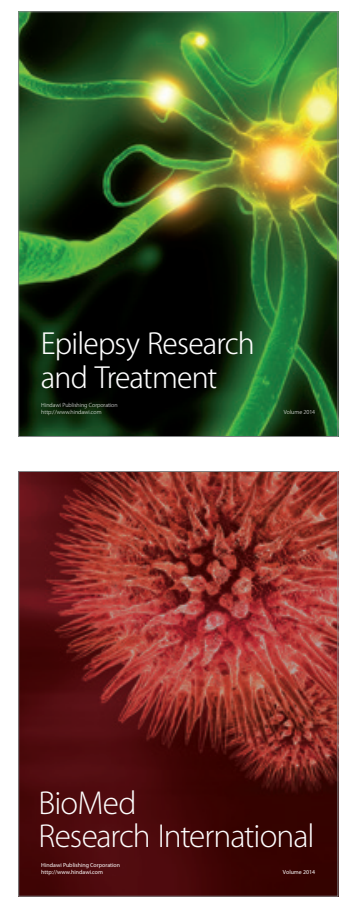

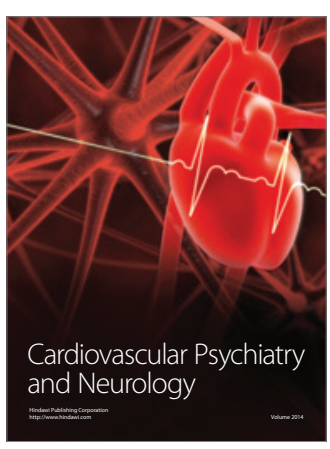

Parkinson's

Disease
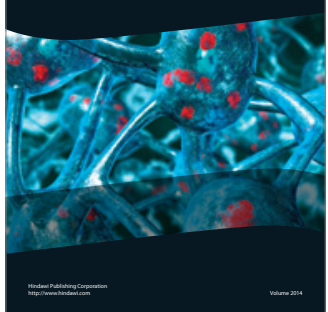